\title{
USING SURFACE WAVE METHOD TO DEFINE A SINKHOLE IMPACT AREA IN A NOISY ENVIRONMENT
}

\author{
Jianghai Xia, ${ }^{1}$ Peter H. Li, ${ }^{2}$ Michael J. Lewis, ${ }^{3}$ Richard D. Miller, ${ }^{1}$ and Choon B. Park ${ }^{1}$ \\ ${ }^{1}$ Kansas Geological Survey, The University of Kansas, Lawrence, KS \\ ${ }^{2}$ Earth Resources Technology, Inc., Jessup, MD \\ ${ }^{3}$ Calvert Cliffs Nuclear Power Plant, Lusby, MD
}

\begin{abstract}
A sinkhole developed at Calvert Cliffs Nuclear Power Plant, Maryland in early 2001. To prevent damage to nearby structures, the sinkhole was quickly filled with dirt (approximately 40 tons). However, the plant had an immediate need to determine if more underground voids existed. The location of the sinkhole was over a groundwater drainage system pipe buried at an elevation of +3 feet (reference is to Chesapeake Bay level). Grade in the sinkhole area is +45 feet. The subsurface drain system is designed to lower the local water table from approximately +20 feet above Bay level to +10 feet. The subsurface drain system is connected to the top of the condenser cooling water discharge conduit at an elevation of -4 feet. The cause of the sinkhole was a subsurface drain pipe that collapsed due to saltwater corrosion of the corrugated metal pipe. The inflow/outflow of sea water and ground water flow caused dirt to be removed from the area where the pipe collapsed.

A high-frequency surface-wave survey was conducted to define the sinkhole impact area. Five surface-wave lines were acquired with limited resources: a 24-channel seismograph with a hammer and an aluminum plate as a source. Although the surface-wave survey at Calvert Cliffs Nuclear Power Plant was conducted at a noise level 50-100 times higher than the normal environment for a shallow seismic survey, the shear (S)-wave velocity field calculated from surface-wave data delineated a possible sinkhole impact area. The S-wave velocity field showed chimney-shaped low-velocity anomalies that were directly related to the sinkhole. Based on $\mathrm{S}$-wave velocity field maps, a potential sinkhole impact area was tentatively defined. S-wave velocity field maps also revealed, depending on the acquisition geometry, one side of the water tunnel of the power plant.
\end{abstract}

\section{Introduction}

Elastic properties of near-surface materials and their effects on seismic wave propagation are of fundamental interest in groundwater, engineering, and environmental studies. Shear (S)-wave velocity is a key parameter in construction engineering. As an example, Imai and Tonouchi (1982) studied P- and S-wave velocities in an embankment, and also in alluvial, diluvial, and tertiary layers, showing that $S$ wave velocities in such deposits correspond to the N-value (blow count) (Craig, 1992), an index value of formation hardness in soil mechanics and foundation engineering.

Surface waves are guided and dispersive. Rayleigh (1885) waves are surface waves that travel along a "free" surface, such as the earth-air interface. Rayleigh waves are the result of interfering P and $\mathrm{S}_{\mathrm{v}}$ waves. The particle motion of Rayleigh waves moving from left to right is elliptical in a counterclockwise (retrograde) direction. The motion is constrained to the vertical plane consistent with the direction of wave propagation (Babuska and Cara, 1991, p. 30). Longer wavelengths penetrate deeper 
than shorter wavelengths for a given mode, in general exhibit greater phase velocities, and are more sensitive to the elastic properties of the deeper layers (Babuska and Cara, 1991, p. 30). Shorter wavelengths are sensitive to the physical properties of surface layers. For this reason, a particular mode of surface waves will possess a unique phase velocity for each unique wavelength leading to dispersion of the seismic signal.

The S-wave velocity can be derived from inverting the phase velocity of the surface (Rayleigh and/or Love) wave (Dorman and Ewing, 1962). For the case of a solid homogenous half-space, the Rayleigh wave travels with a velocity of approximately $0.9194 v$, where $v$ is the $S$-wave velocity in the half space (Sheriff and Geldart, 1982, p. 49) and is not dispersive. In the case of one layer on top of a solid homogenous half-space, dispersion of the Rayleigh wave occurs when the wavelengths of the Rayleigh wave are in the range of 1 to 30 times the layer thickness (Stokoe et al., 1994). Stokoe et al. also show that the Rayleigh wave travels with a velocity of approximately $0.9194 v_{1}\left(v_{1}\right.$ is the S-wave velocity in the layer) when the wavelengths of the Rayleigh wave are shorter than the layer thickness. For the wavelengths longer than 30 times the layer thickness, the Rayleigh wave phase velocity is approximately equal to $0.9194 v_{2}$ ( $v_{2}$ is the $\mathrm{S}$-wave velocity in the half space).

Ground roll is a particular type of Rayleigh wave that travels along or near the ground surface and is usually characterized by relatively low velocity, low frequency, and high amplitude (Sheriff, 1991, p. 143). Stokoe and Nazarian (1983) and Nazarian et al. (1983) presented a surface-wave method, Spectral Analysis of Surface Waves (SASW), which analyzes the dispersion curve of ground roll to produce near-surface S-wave velocity profiles. SASW has been widely applied to many engineering projects (e.g., Sanchez-Salinero et al., 1987; Sheu et al., 1988; Stokoe et al., 1989; Gucunski and Woods, 1991; Hiltunen, 1991; Stokoe et al., 1994).

Inversion of dispersion curves to estimate S-wave velocities deep within the Earth was first attempted by Dorman and Ewing (1962). Song et al. (1989) related sensitivity of model parameters to several key parameters by modeling and presentation of two real examples where surface waves were used to obtain S-wave velocities. Turner (1990) examined the feasibility of inverting surface waves (Rayleigh and Love) to estimate S-wave and P-wave velocities. Dispersion curves are inverted using least-squares techniques in SASW methods (Stokoe and Nazarian, 1983; Nazarian et al., 1983). Rix and Leipski (1991) examined the influence of the number of dispersion data, the maximum wavelength, and distribution of dispersion data with wavelength on the accuracy and resolution of S-wave velocity profiles.

A research project started at the Kansas Geological Survey in 1995 estimated S-wave velocity from ground roll since 1995. Based on their experience, the fundamental-mode phase velocities, when calculated with high accuracy (e.g., Xia et al., 2000b), can generally provide reliable S-wave velocities $( \pm 15 \%)$. The accuracy can be increased if higher modes of surface waves are available and included in the inversion process (Xia et al., 2000a). Recent advances in the use of surface waves for near-surface imaging incorporated Multichannel Analysis of Surface Waves (MASW) (Park et al., 1996, 1999a, and 1999b; Xia et al., 1997, 1999, and 2000b) with a standard common depth point (CDP) roll-along acquisition format (Mayne, 1962) similar to conventional petroleum exploration data acquisition. Combining these two uniquely different approaches to acoustic imaging of the subsurface allows high confidence, non-invasive delineation of horizontal and vertical variations in near-surface material properties (Miller et al., 1999, Xia et al., 2000c). 
A sinkhole developed in the Tank Farm area at Calvert Cliffs Nuclear Power Plant, Maryland in early 2001 (Figure 1). To prevent damage to nearby structures, the sinkhole was quickly filled with dirt (approximately 40 tons). However, the plant had an immediate need to determine if more underground

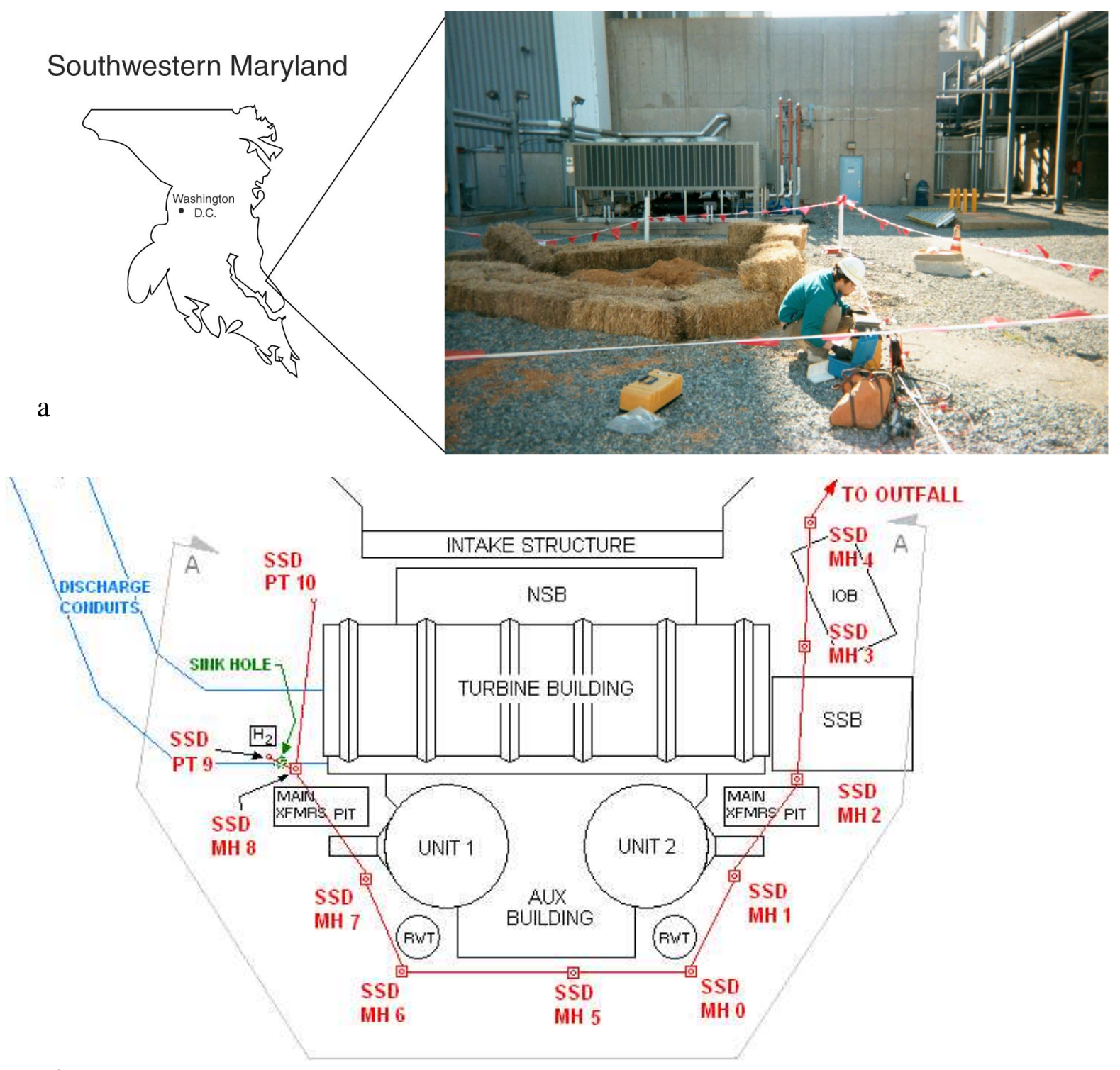

b

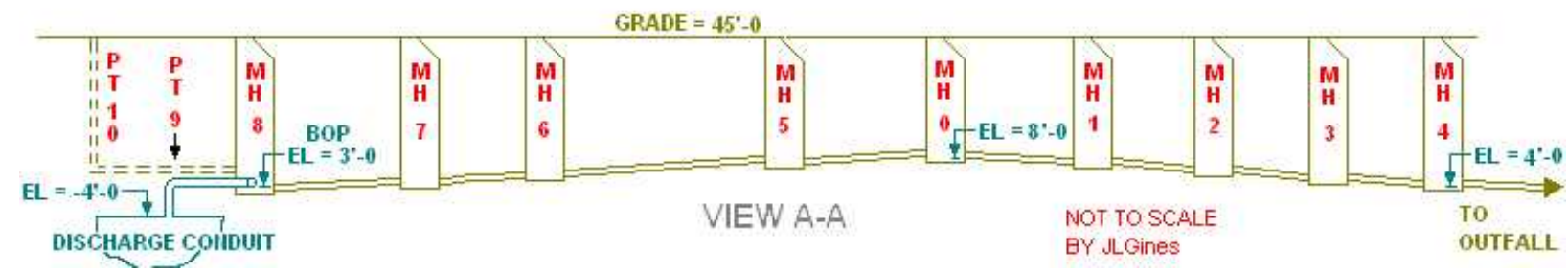

Figure 1. A sinkhole surrounded by straw bales at Calvert Cliffs Nuclear Power Plant, Calvert County, Maryland. The structure at the back of the photo is the turbine building. The transformer is located to the right in the photo (a). The groundwater drainage system is shown in (b). 
voids existed. The location of the sinkhole was over a groundwater drainage system pipe buried at an elevation of +3 feet (reference is to Chesapeake Bay level). Grade in the sinkhole area is +45 feet. The subsurface drain system is designed to lower the local water table from approximately +20 feet above Bay level to +10 feet. The subsurface drain system is connected vertically into the top of the condenser cooling water discharge conduit at an elevation of -4 feet. The sinkhole was located approximately 15 feet horizontally from this connection to the conduit. The static pressure in the conduit forces saltwater up into the corrugated metal subsurface drain pipe. Because the conduit discharges to the Chesapeake Bay, this static pressure varies with the tide. The collapsed section of pipe was in the tidal zone. The tidal action (inflow/outflow) and groundwater flow caused dirt to be removed from the area around the collapsed pipe. The discharge conduit is a monolithic concrete structure 61 feet wide and 20 feet tall (a rectangular cross section) and approximately 800 feet long. The top of the conduit is approximately 49 feet below grade. The conduit is divided into four separate tunnels, each approximately 12 feet by 12 feet in dimension. Each tunnel carries a cooling water flow of 600,000 gallons per minute (total flow in the conduit is 2.4 million gallons per minute).

The area potentially impacted by the sinkhole needs to be defined to prevent further damage and assure the safety of the plant. Voids can be difficult to detect from surface investigations and can be expensive to detect with hit and miss drilling. Changes in shear wave velocity may be expected at the boundary between unconsolidated materials and consolidated bedrock as well as unconsolidated and fill materials. The surface-wave method was proposed to define the sinkhole impact area. This study will focus on the following goals and objectives: 1) processing noisy surface-wave data, 2) feasibility of defining a sinkhole impact area at least $50 \mathrm{ft}$ deep by using the MASW method with fundamental mode data acquired with the standard CDP roll-along acquisition format, and 3) evaluation of effective depth of imaging.

\section{The Method}

Surface-wave imaging has shown great promise detecting shallow tunnels (Xia et al., 1998) and bedrock surfaces (Miller et al., 1999; Xia et al., 2000c). Extending this imaging technology to include lateral variations in lithology has required a unique approach incorporating MASW and CDP methods. Integrating these techniques provides a 2-D continuous shear wave velocity profile of the subsurface. Signal enhancement resulting from determination of a dispersion curve using upwards of 60 closely spaced receiving channels and the calculation of a dispersion curve every $2 \mathrm{ft}$ or so along the ground surface provides a unique, relatively continuous view of the shallow subsurface. This highly redundant method enhances the accuracy of the calculated shear wave velocity and minimizes the likelihood that the irregularities associated with an occasional erratic dispersion curve will corrupt the data analysis.

The MASW method is based on the fact that the S-wave velocity is the dominant influence on Rayleigh wave for a layered earth model, which assures us that inverting phase velocities will give us an S-wave velocity profile (1-D S-wave velocity function, Vs vs. depth) at the center of a geophone spread. Because data are acquired in the standard CDP format, phase velocities of ground roll can be extracted from each shot gather so that numerous 1-D S-wave profiles along a survey line can generated. A twodimensional vertical section of S-wave velocity can be generated by any contouring software.

A number of multichannel records should first be collected in the standard CDP roll-along acquisition format. If a swept source is used, the recorded data should be converted into a correlated format, which is equivalent to data acquired with an impulsive source. Surface impact sources and receivers 
with a low response frequency, normally less than $8 \mathrm{~Hz}$, should be chosen to acquire surface-wave data. Data acquisition parameters, such as source-receiver offset, receiver spacing, etc., should be set to enhance ground-roll signals (Park et al., 1999a).

Once the data collection is completed, phase velocities (dispersion curves) of the ground roll of each shot gather should be calculated. The frequency range and phase velocity range of the ground roll need to be determined by analyzing data along the entire line. These two ranges are very important constraints to correctly extract the dispersion curve from each shot gather. They not only help eliminate noise such as body wave, higher mode of Rayleigh waves, etc., during calculation of phase velocities (Park et al., 1999a), but also assist in defining the thickness of the layer model.

Inversion should be performed on each dispersion curve to generate an S-wave velocity vs. depth profile (Xia et al., 1999b). The inverted S-wave velocity profile should be located in the middle of the receiver spread (Miller and Xia, 1999). Initial models are a key factor to assure convergence of the inversion process. After processing more than five thousand shots of real data and countless sets of modeling data, initial models defined by Xia et al.'s algorithm (1999b) are generally converged to models that are acceptable in geology and also fit the dispersion curve in a given error range. The number of layers is chosen between five to twenty in most of our experience, based on the accuracy of surface-wave data, an investigation depth, and required resolution of S-wave velocity. The thickness of each layer varies based on the depths of interest. For example, for a geological problem with a depth of interest of $50 \mathrm{ft}$ we may choose a ten-layer model with the first three layers being $3 \mathrm{ft}$ thick, the next three layers $6 \mathrm{ft}$ thick, the last three layers $10 \mathrm{ft}$ thick, and a half space. The inverted S-wave velocity profile for each shot gather is the result of horizontally averaging across the length of the geophone spread.

Gridding algorithms, such as kriging, minimum curvature, etc., may be used to generate a twodimensional contour map of the S-wave velocity of a vertical section. With density information, a shear modulus section can be generated simultaneously. Two-dimensional data processing techniques, such as regression analysis, can be easily applied to a vertical section of S-wave velocity to enhance local anomalies.

On a 2-D S-wave velocity map, the bedrock surface is usually associated with high S-wave velocity gradients, while fracture zones, voids, buried landfill edges, and the like may be indicated by Swave anomalies such as low velocity zones. The general procedure for generating a 2-D S-wave velocity map is summarized as follows (Figure 2).

1. Collection of a number of multichannel records in a standard CDP roll-along acquisition format. The field data acquisition parameters are chosen to enhance broad band ground roll. If a swept source is used, the recorded data should be converted into correlated format, which is equivalent to data acquired with an impulsive source.

2. Calculation of the phase velocity of the ground roll of each shot gather, Once the data collection is completed.

3. Inversion of the phase velocity to generate an S-wave velocity vs. depth profile at each source location.

4. Generation of a 2-D contour map of the S-wave velocity of a vertical section by using a gridding algorithm, such as kriging, minimum curvature, etc. With density information, a shear modulus section can be generated simultaneously. 


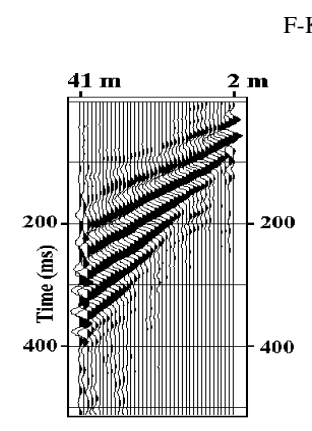

Multichannel data
F-K Transform

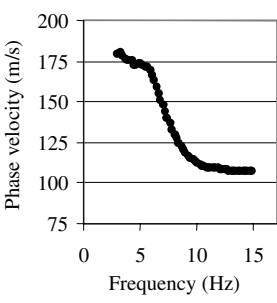

A dispersion curve
Inversion

Contouring

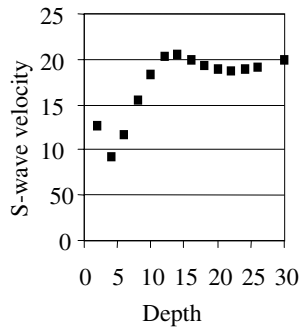

An S-wave velocity profile

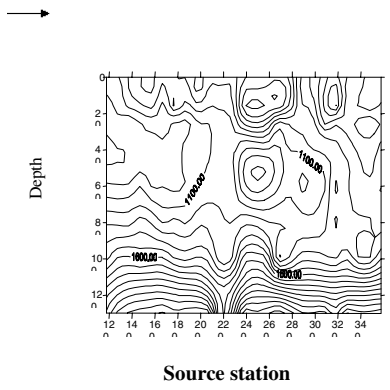

A 2-D S-wave velocity map

Figure 2. A diagram of construction of 2-D S-wave velocity map by the MASW method. Multichannel raw field data are acquired in the CDP roll-along format. Rayleigh wave phase velocities are extracted from the field data in the F-K domain. Phase velocities are inverted for a shear-wave velocity profile ( $\mathrm{V}_{\mathrm{s}}$ vs. depth). Finally, a 2-D S-wave velocity map is generated with contouring software.

\section{Data Acquisition}

Because the depth to the drainage tunnel is $45 \mathrm{ft}$, the investigation depth for this project was approximately $50 \mathrm{ft}$. Three data acquisition parameters were determined by using the investigation depth: nearest source-geophone offset, geophone interval, and length of the geophone spread (the distance from the first geophone to the last geophone).

The nearest source-geophone offset is normally chosen as half the investigation depth (Park et al., 1999b), or in this case, $24 \mathrm{ft}$. With a 24-channel recording system, the geophone spread is critical to maintain the proper resolution in the frequency-velocity domain, thereby allowing the software to accurately pick phase velocities of surface waves. The half wavelength is the effective penetrating depth of surface waves. In this project, we need to record a 100-ft wavelength component of surface waves. This condition determined the geophone spread would be $92 \mathrm{ft}$ with a geophone interval of $4 \mathrm{ft}$.

Earth Resource Technology, Inc. acquired the surface-wave data. Data were collected using a 24channel StrataView seismograph with a 12-lb hammer and a $1^{\prime} \times 1^{\prime}$ aluminum plate as the seismic source in a standard CDP roll-along acquisition format to generate $S$-wave velocity sections. Twentyfour $4.5 \mathrm{~Hz}$ vertical-component geophones were deployed on the same geophone interval $(4 \mathrm{ft})$ with $24 \mathrm{ft}$ from the source to the nearest geophone along five lines (Figure 3). Six impacts at each shot station were vertically stacked to increase the signal-to-noise ratio.

Five lines were designed around the sinkhole based on accessibility (Figure 3), and 137 shots of surface-wave data were collected along those lines. Total line length of the surface-wave survey was $1102 \mathrm{ft}$. Total imaging length of the survey was $522 \mathrm{ft}$. The data were acquired in an extremely noisy environment. The turbine and transformer of the power plant were running during data acquisition. The noise level was as high as 100 millivolts on the noise monitor of the StrataView seismograph, which is more than 50-100 times higher than the noise level for a normal shallow seismic survey. At this noise 


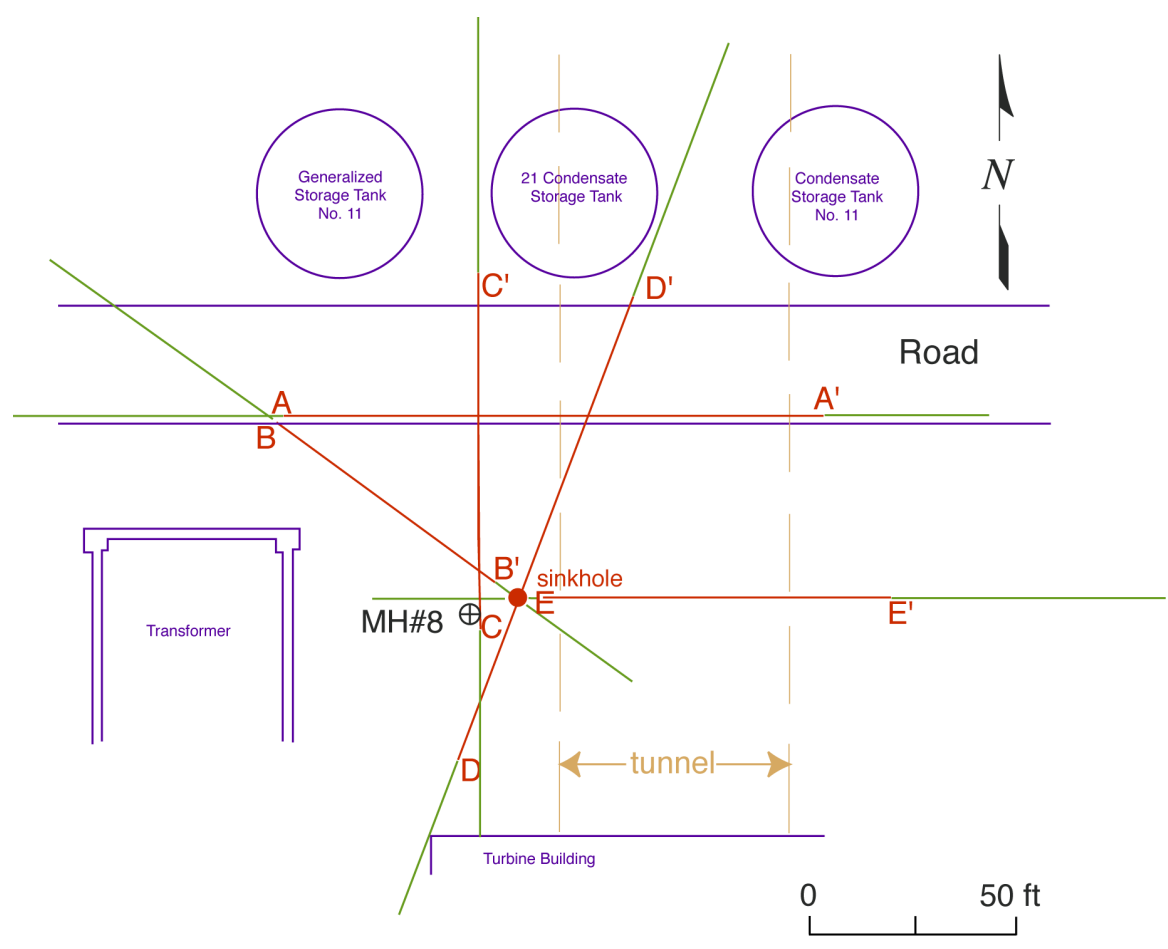

Figure 3. Location of surface-wave seismic lines. The red indicates that part of the line that was imaged by the survey.

level, no one would attempt to acquire body-wave seismic data. Surface materials consisted of gravel and asphalt. It was difficult to generate seismic energy on the gravel surface.

\section{Data Processing}

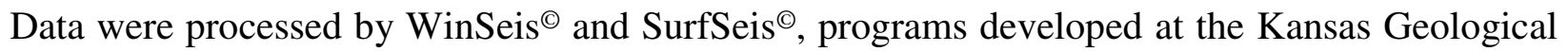
Survey. A pre-processing flow of the surface-wave data included bandpass filtering (a trapezoid with four frequencies of $3,6,40$, and $60 \mathrm{~Hz}$ ), automatic gain control scaling (AGC) with a time window of 100 milliseconds (ms), and f-k filtering (a filtered pie defined by two lines with slopes of $-3 \mathrm{~ms} /$ trace and $-9 \mathrm{~ms} /$ trace, respectively). The bandpass filter and AGC were used to filter unwanted frequency components, mostly body waves, and to balance the surface-wave spectrum, respectively. The f-k filter was employed to suppress noise from the turbine and transformer from the end of a line (Figures $4 a-4 b$ ).

SurfSeis ${ }^{\odot}$ managed to pick up dispersion curves from $13 \mathrm{~Hz}$ to $27 \mathrm{~Hz}$ for all shots (Figure 4c). Wavelengths of phase velocities ranged from $25 \mathrm{ft}$ to $240 \mathrm{ft}$. A five-layer model, with thickness of $10 \mathrm{ft}$, $10 \mathrm{ft}, 15 \mathrm{ft}, 15 \mathrm{ft}$, and the half-space, was chosen during inversion processing. The layer thickness of the model should be controlled by the shortest wavelength of the surface waves. This low resolution model was chosen to stabilize the inversion processing (Xia et al., 2000a) because of extremely noisy data. 
RECORD \# 1108

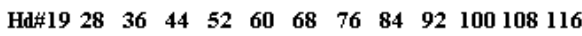

$\begin{array}{llllllllllllll}\text { Trc\# } & 2 & 4 & 6 & 8 & 10 & 12 & 14 & 16 & 18 & 20 & 22 & 24\end{array}$

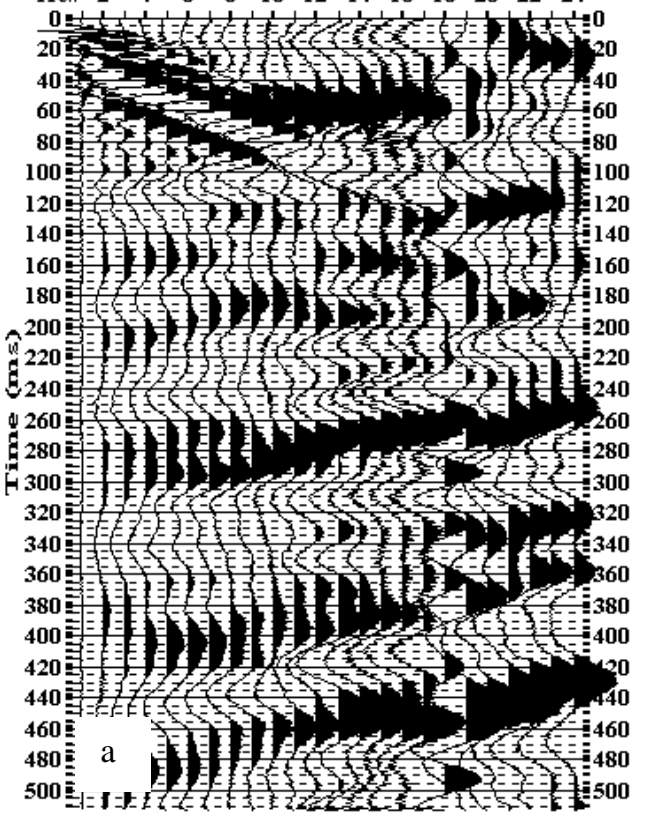

RECORD \# 1108

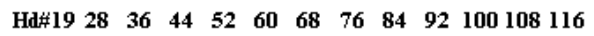

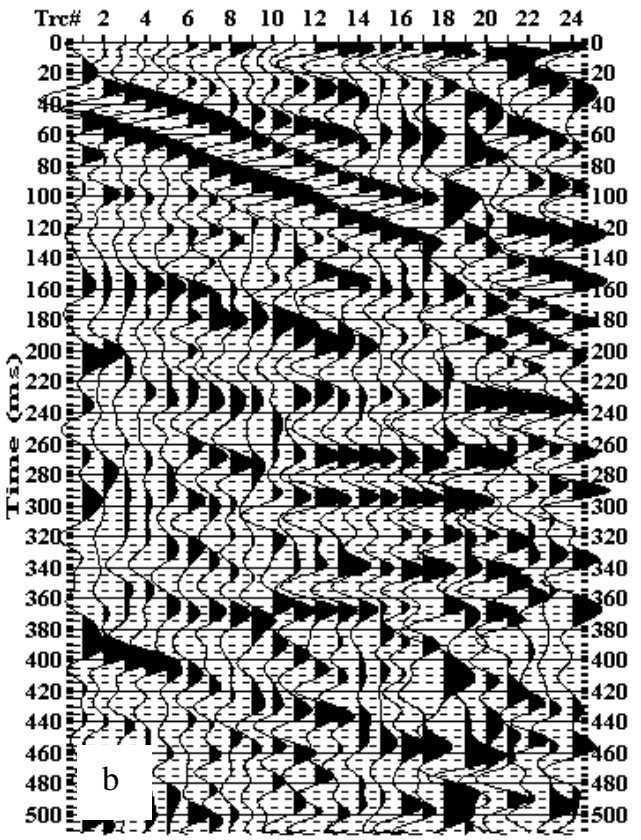

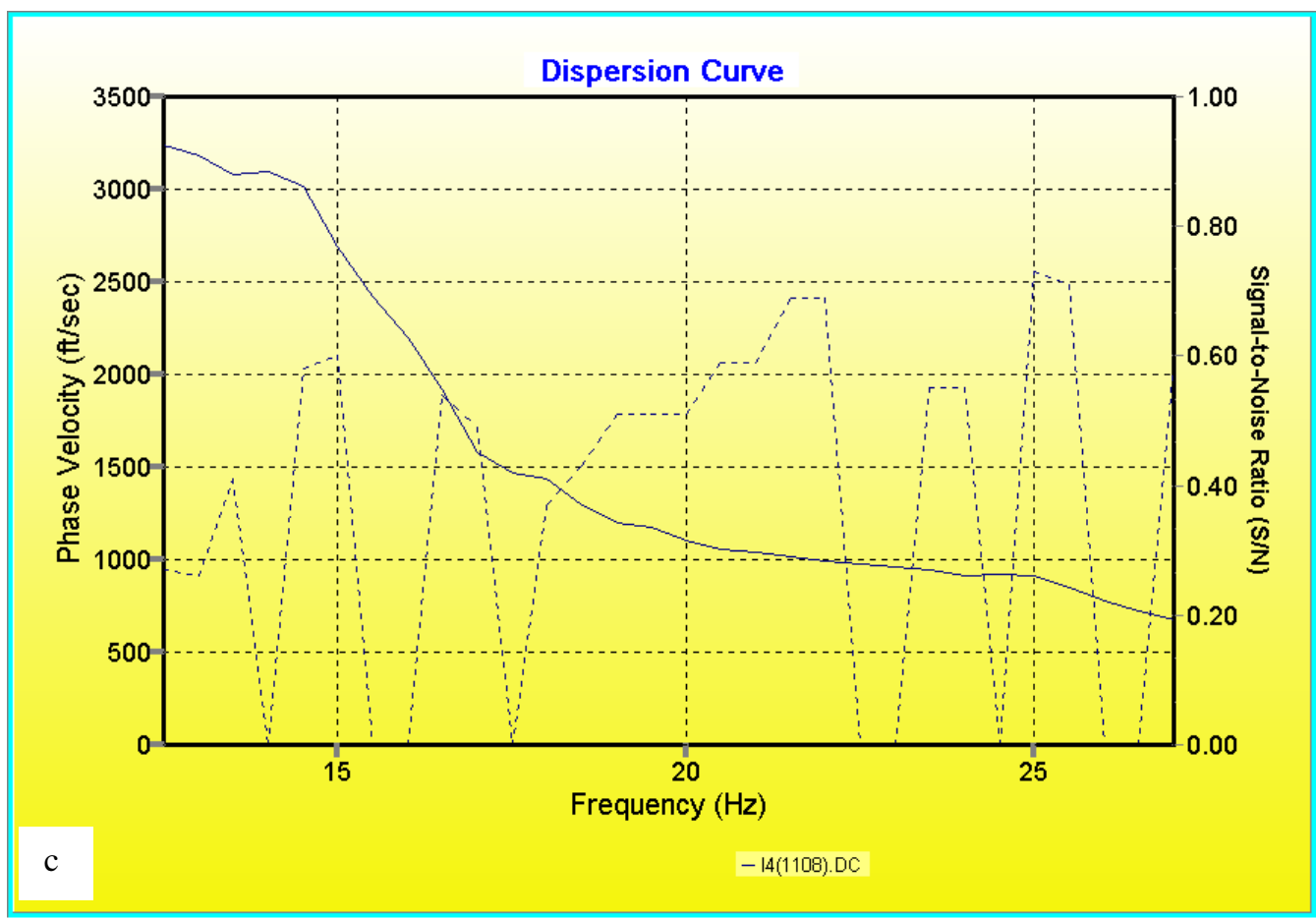

Figure 4. An example of field shot gather: a) raw data, b) data after a bandpass filtering, an AGC scaling, and an f-k filtering, and c) phase velocities (the solid line) and a signal to noise ratio curve (the dash line). 
Phase velocities of surface waves were inverted into S-wave velocities of the layered earth model for each shot. The inverted S-wave velocity profile was placed at the center of a geophone spread of each shot gather. The contouring software Surfer ${ }^{\odot}$ was finally used to generate 2-D S-wave velocity fields (Figures 5-8) of each line.

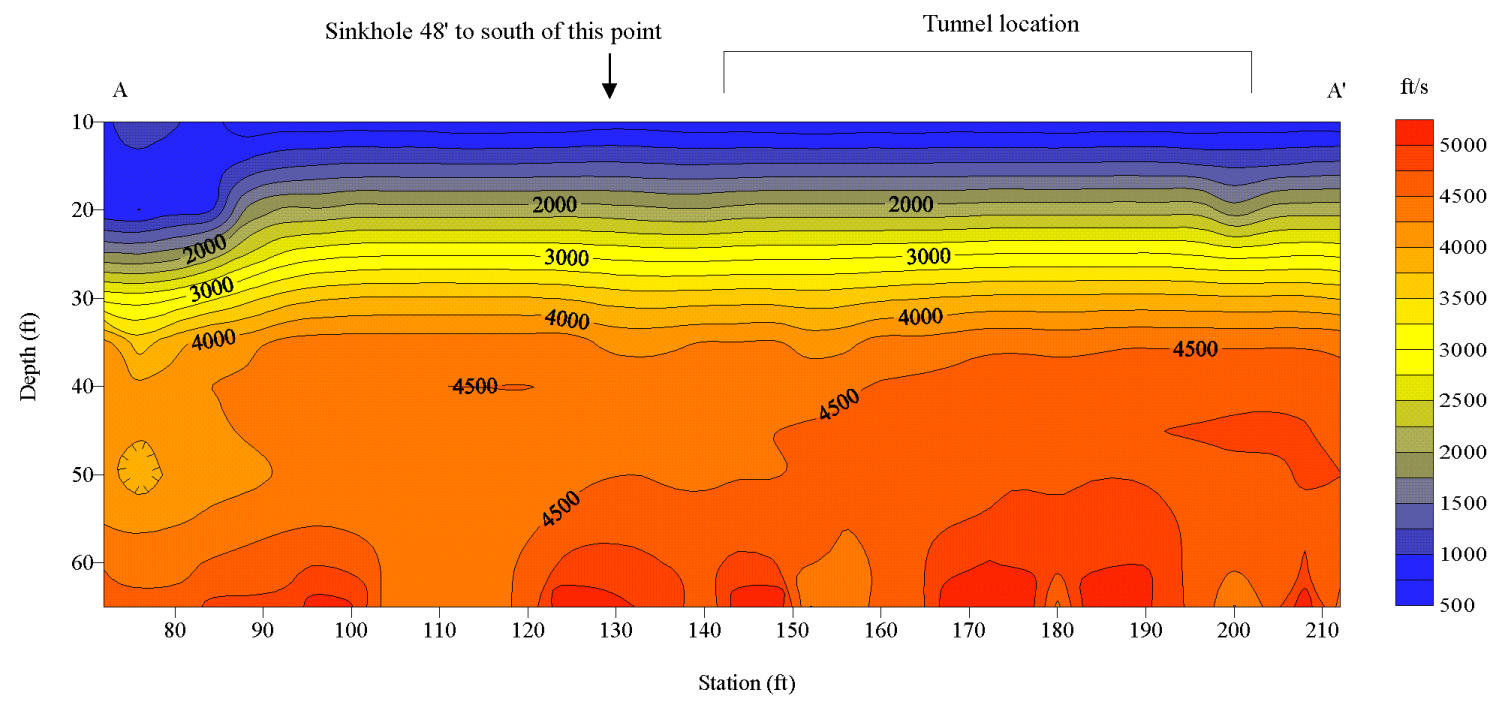

Figure 5. S-wave velocity field of line A-A'. A contour interval is $250 \mathrm{ft} / \mathrm{s}$.

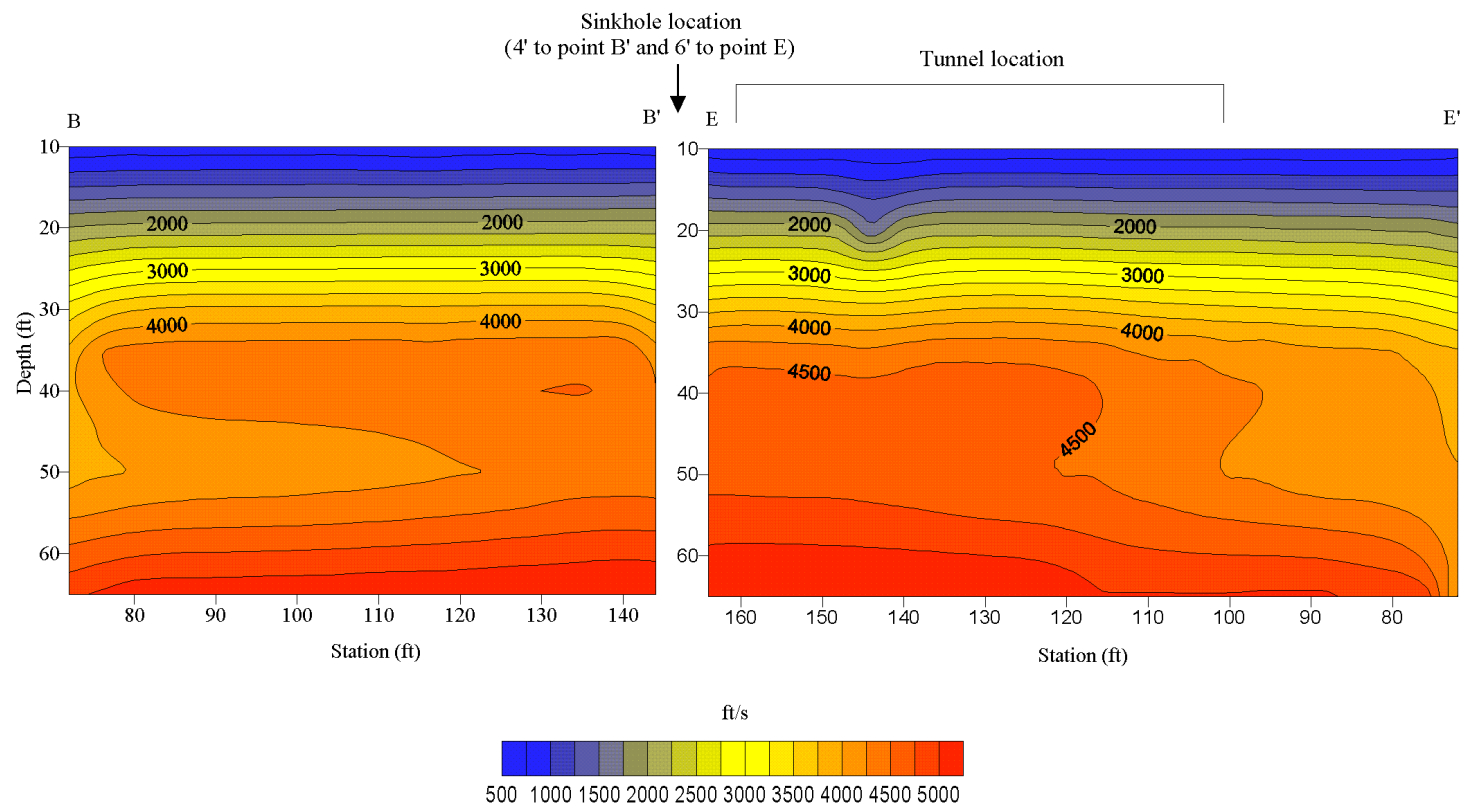

Figure 6. S-wave velocity field of lines B-B' and E-E'. A contour interval is $250 \mathrm{ft} / \mathrm{s}$. 


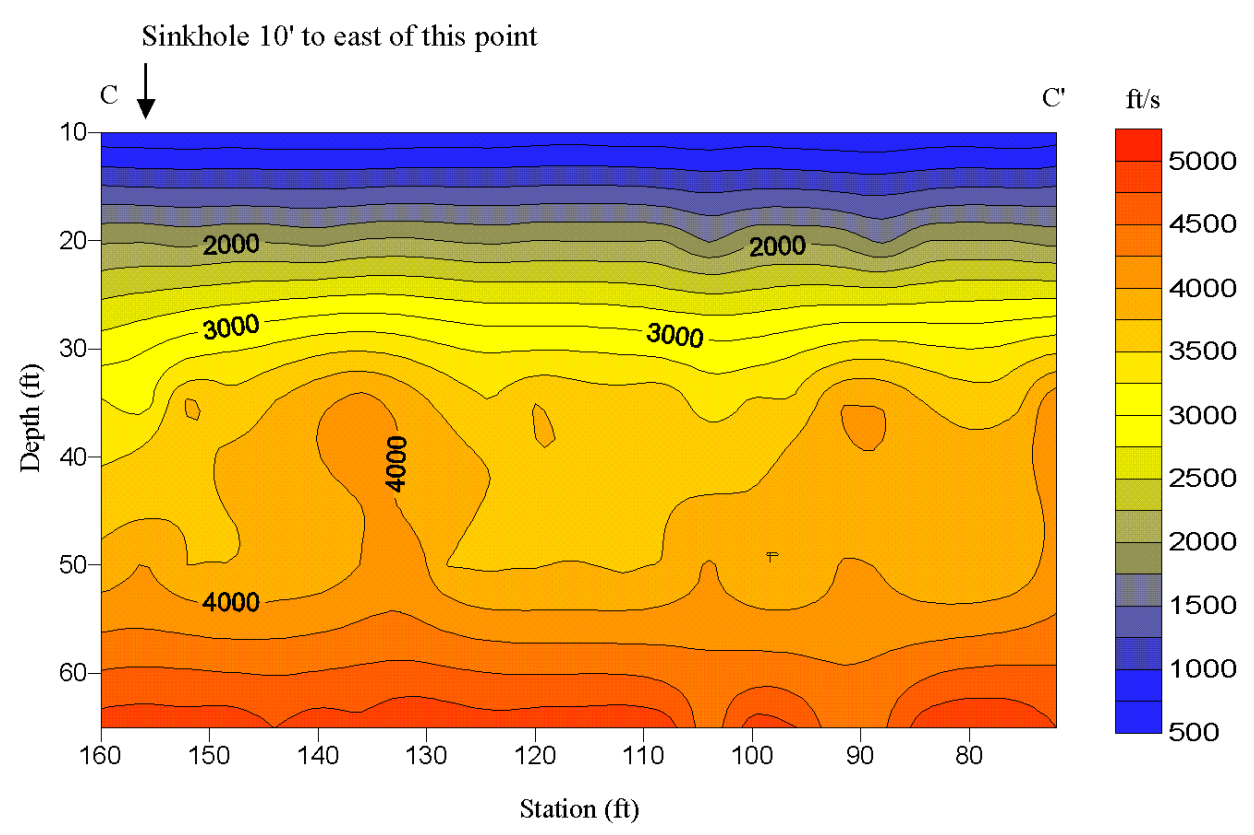

Figure 7. S-wave velocity field of line C-C'. A contour interval is $250 \mathrm{ft} / \mathrm{s}$.

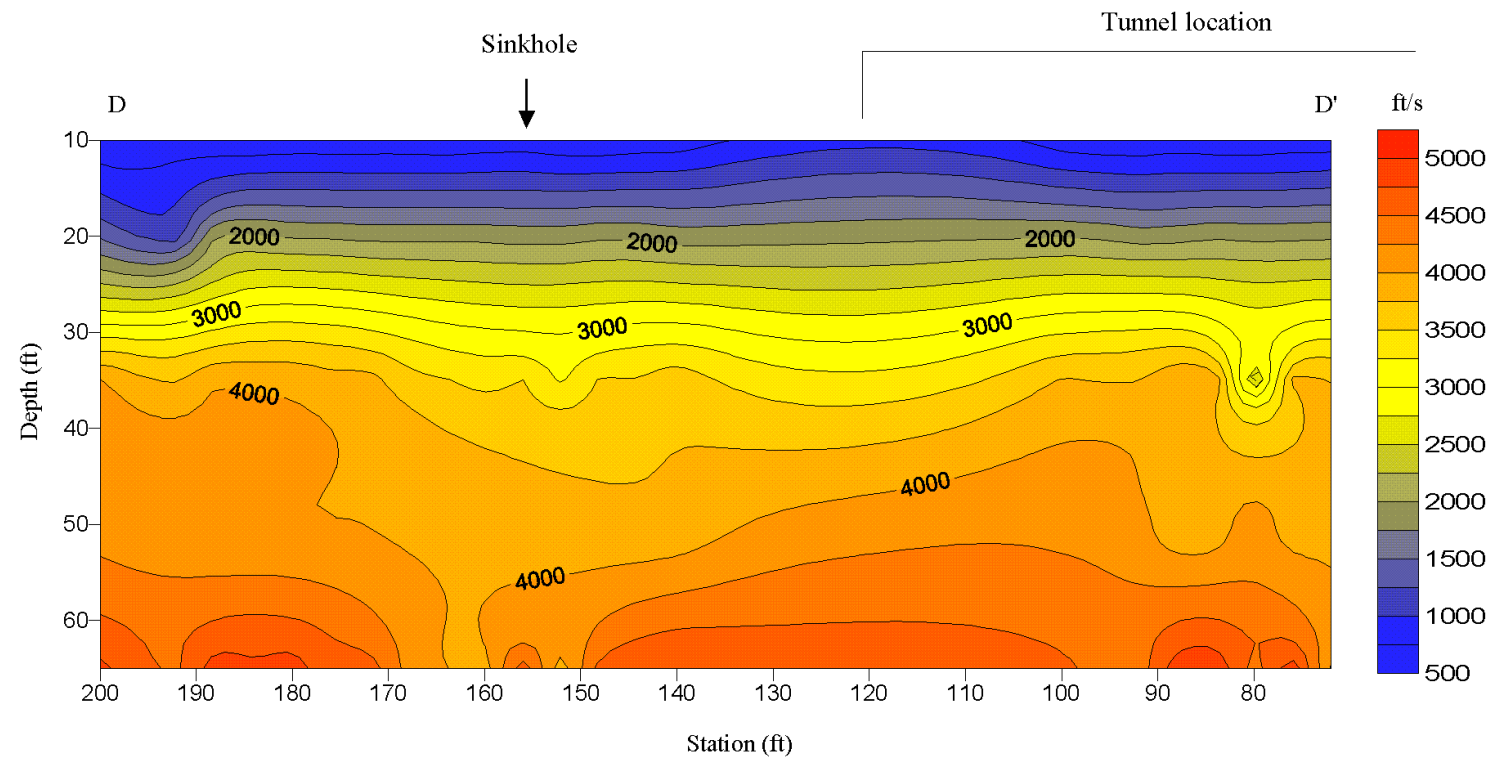

Figure 8. S-wave velocity field of line D-D'. A contour interval is $250 \mathrm{ft} / \mathrm{s}$. 


\section{Sinkhole Impact Area}

The sinkhole was filled by dirt to prevent additional damage. Although the refilling reduced the velocity contrast in the sinkhole impact area, we expect that the new dirt is much less compacted than surrounding materials so the sinkhole impact area will still show anomalies with a lower S-wave velocity. An imaging point of the surface-wave method is located in the center of the geophone spread of each shot (Miller and Xia, 1999). Because of the limited access to the area surrounding the sinkhole, only line D-D' (Figure 8) contains imaging points that traverse the sinkhole. The sinkhole was located at station 155 of line D-D'. A striking relative lower S-wave velocity field from stations 150 to 170 below $40 \mathrm{ft}$ of depth is shown in Figure 8. Based on its low S-wave velocity, it is likely that the area that possesses lower S-wave velocity along line D-D' was impacted by the sinkhole. It is also interesting to see that the sinkhole was located at station 155 instead of 160, the center of the impacted area. This might be due to the smear effect of S-wave velocities at deeper depths. The water tunnel located approximately at station 120 and less on line D-D' showed a higher S-wave velocity. This tunnel might cause a slight shift in the interpreted impacted area on the S-wave velocity field.

Line A-A' (Figure 5) possesses a relative lower S-wave velocity field around station 110, similar to that shown on line D-D' around the sinkhole. A chimney-shape S-wave velocity field from stations 100 to 120 below $40 \mathrm{ft}$ of depth indicates a possible area impacted by the sinkhole. We suggest that the sinkhole impact area extends northward at least to line A-A'. The north-south line C-C' seems to support this suggestion.

The S-wave velocity field of line C-C' (Figure 7) presents an anomalous low that covers the entire line at a depth of $40 \mathrm{ft}$ to $50 \mathrm{ft}$. This anomaly reveals a possible sinkhole impact area along line C-C'. These results indicate that the chimney-shape anomaly shown on line A-A' was most likely related to the sinkhole. Based on previous interpretation of low S-wave velocity anomalies, we delineate a possible sinkhole impact area in Figure 9 even with the limited accessibility and the limited resolution of S-wave velocity fields. The potential sinkhole impact area was covered most part of line C-C' that was between lines A-A' and E-E'. The area was approximately $60 \mathrm{ft}$ lone and $20 \mathrm{ft}$ wide. The depth of the potential impact volume was at 40 to $50 \mathrm{ft}$.

According to the amount of dirt required to fill the sinkhole (40 tons $=40 \times 2000 \mathrm{lb}=40 \times 900$ $\mathrm{kg}$ ), the volume of the void immediately associated with the sinkhole is estimated to be around $26 \mathrm{~m}^{3}$ (assuming a density of dirt $1,400 \mathrm{~kg} / \mathrm{m}^{3}$ ). The volume of the void will be larger than $26 \mathrm{~m}^{3}$ if the dirt density is less than $1,400 \mathrm{~kg} / \mathrm{m}^{3}$. The low S-wave velocity zone at depths of 40 to $50 \mathrm{ft}$ along line C-C' (Figure 7) suggests the vertical impact dimension is around $10 \mathrm{ft}(3 \mathrm{~m})$. We also see the impact length along both lines A-A' (105 to 115) and D-D' (155 to 165) are around $10 \mathrm{ft}(3 \mathrm{~m})$. Thus, a northwestsoutheast distance for an interpreted sinkhole impact area is approximately $10 \mathrm{ft}(3 \mathrm{~m})$, assuming the impact area is approximately a rectangle. These results suggest the immediately impacted volume after dirt filling is a symmetrical cube with a $3 \mathrm{~m}$ in length (a shaded area in Figure 9).

The S-wave velocity field of line E-E' (Figure 6) shows a dramatic S-wave velocity low at station 144 at a depth of $20 \mathrm{ft}$. This suggests that this spot may also be affected by the sinkhole or other voids. 


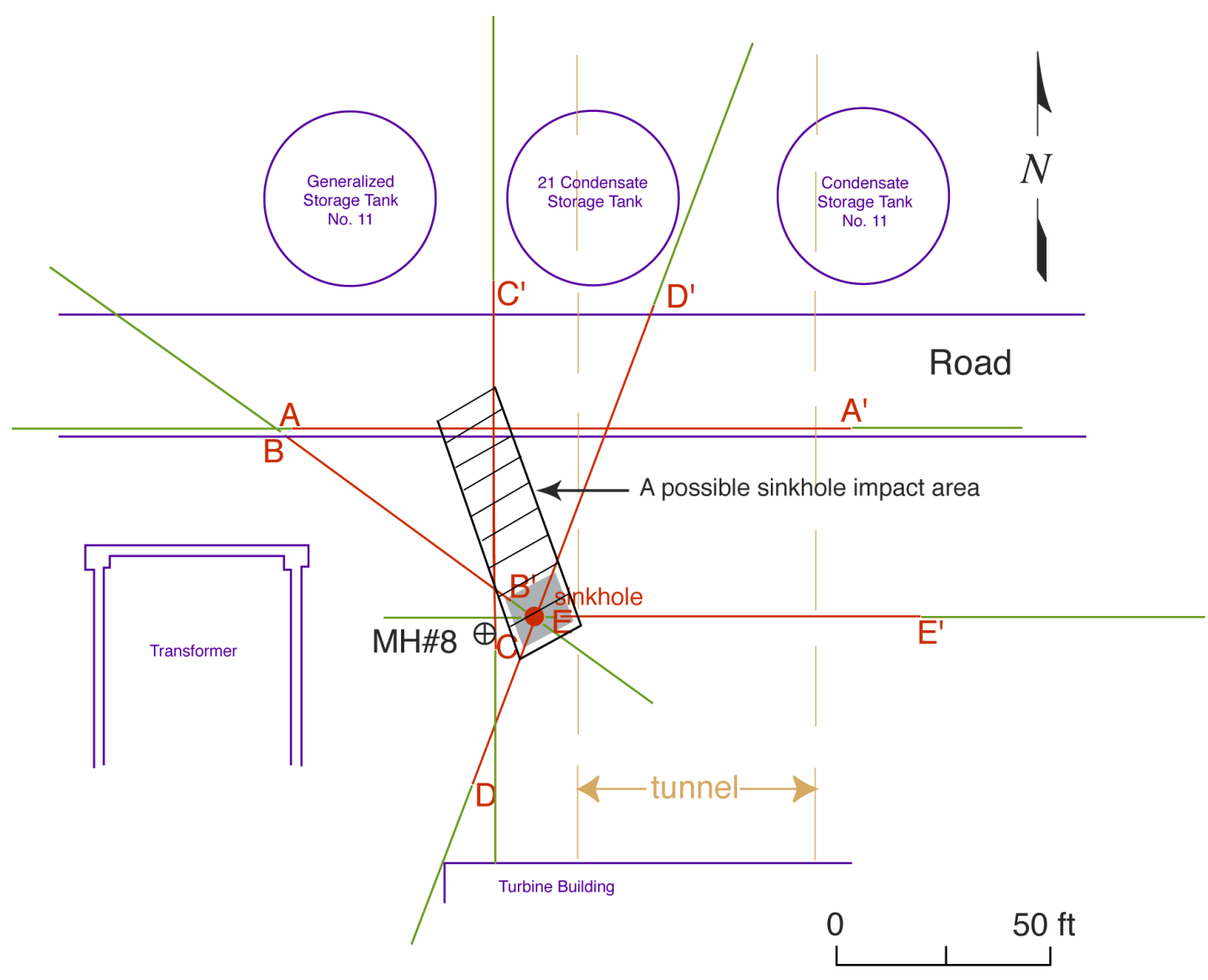

Figure 9. A possible sinkhole impact area interpreted from surface-wave data and an immediate sinkhole impact area (shaded).

\section{Signatures from Tunnel}

Three lines-A-A', D-D', and E-E' - cross the 60-ft wide water tunnel. It was interesting to see how the $\mathrm{S}$-wave velocity field reveals the water tunnel. There was an obvious $\mathrm{S}$-wave velocity increase at depths of around $45 \mathrm{ft}$ at station 145 on line A-A' (Figure 5). The contour line at 4,500 ft/s is associated with the velocity increase. The horizontal location (station 145) and depth (45 ft) of the S-wave velocity increase correspond to the spatial location of the west edge of the tunnel. We see the same results on line E-E' (Figure 6); the contour line at 4,250 ft/s is associated with the S-wave velocity increase and suggests the east edge of the tunnel. That the tunnel was revealed by the contour lines with different velocity values provides an indication of the resolution of the surface-wave method in this environmental setting. Due to the noise level, the difference of $250 \mathrm{ft} / \mathrm{s}$ in S-wave velocity maps did not surprise us.

It is interesting to note that the S-wave velocity field reveals only one side of the tunnel. Based on the data-acquisition geometry, the source was on the west side of the geophone spread for line A-A' and on the east side of the geophone spread for line E-E'. The data-acquisition geometry and S-wave velocity field suggest that surface waves change their behavior significantly in response to S-wave velocities of materials when they propagate from a normal zone and then cross to an anomalous zone. 
Surface-wave fields, however, may not be sensitive enough to reveal the edge of the anomalous zone and the normal zone when surface waves cross over the anomalous zone and enter the normal zone. This might be due to low seismic energy at far offset geophones so that surface waves are not able to detect the other side of tunnel. We will verify this phenomenon in future studies.

We see little indication of the existence of the tunnel from line D-D' (Figure 8). The sources were on the north side of the geophone spread for this line. The surface is covered by gravel on the north side of the road. It was difficult to generate seismic energy and also difficult for seismic energy to propagate on this portion of the line. In addition to the extremely noisy environment, these difficulties may explain why the S-wave velocity field did not reveal the tunnel.

\section{Conclusions}

The surface-wave survey was conducted with limited resources: a 24-channel seismograph with a hammer and an aluminum plant as a source. Although the surface-wave survey at Calvert Cliffs Nuclear Power Plant was conducted at a noise level 50-100 times higher than a normal environment for a shallow seismic survey, the S-wave velocity field calculated from surface-wave data delineated a possible sinkhole impact area. Depending on the source-geophone geometry, the S-wave velocity field revealed one side of the tunnel. Future study should examine why only one side of the tunnel was revealed on the $\mathrm{S}$-wave velocity maps.

\section{Acknowledgements}

We greatly appreciate Mary Brohammer and Julia Shuklaper for their efforts in preparation of this manuscript.

\section{References}

Babuska, V., and Cara, M., 1991, Seismic anisotropy in the Earth: Kluwer Academic Publishers, Boston.

Craig, R.F., 1992, Dirt mechanics (fifth edition): Chapman \& Hall, New York.

Dorman, J., and Ewing, M., 1962, Numerical inversion of seismic surface wave dispersion data and Crust-Mantle structure in the New York-Pennsylvania area: J. Geophys. Res., 67, 5227-5241.

Gucunski, N., and Wood, R.D., 1991, Instrumentation for SASW testing, in Geotechnical special publication no. 29, recent advances in instrumentation, data acquisition and testing in dirt dynamics, edited by S.K. Bhatia, and G. W. Blaney: American Society of Civil Engineers, 1-16.

Hiltunen, D.R., 1991, Nondestructive evaluation of pavement systems by the SASW method: Geotechnical News, BiTech Publishers Ltd., Vancouver, B. C., September, 22-25.

Imai, T., and Tonouchi, K., 1982, Correlation of N-value with S-wave velocity: Proc. of 2nd Europ. Sympo. on Penetration Testing, 67-72.

Mayne, W.H., 1962, Horizontal data stacking techniques: Supplement to Geophysics, 27, 927-937.

Miller, R.D., Xia, J., Park, C.B., Ivanov, J., 1999, Multichannel analysis of surface waves to map bedrock: The Leading Edge, 18, 1392-1396. 
Miller, R.D., and Xia, J., 1999, Feasibility of seismic techniques to delineate dissolution features in the upper $600 \mathrm{ft}$ at Alabama Electric Cooperative's proposed Damascus site, Interim Report: Kansas Geological Survey Open-file Report 99-3.

Nazarian, S., Stokoe II, K. H., and Hudson, W.R., 1983, Use of spectral analysis of surface waves method for determination of moduli and thicknesses of pavement systems: Transportation Research Record No. 930, 38-45.

Park, C.B., Miller, R.D., and Xia, J., 1996, Multi-channel analysis of surface waves using Vibroseis (MASWV): Technical Program with Biographies, SEG, 66th Annual Meeting, Denver, Colorado, 68-71.

Park, C.B., Miller, R.D., Xia, J., Hunter, J.A., and Harris, J.B., 1999a, Higher mode observation by the MASW method: SEG, 69th Annual Meeting, Houston, TX, 524-527.

Park, C.B., Miller, R.D., and Xia, J., 1999b, Multi-channel analysis of surface waves: Geophysics, 64, 800-808.

Rayleigh, L., 1885, On waves propagated along the plane surface of an elastic solid: Proc. Lond. Math. Soc., 17, 4.

Rix, G.J., and Leipski, A.E., 1991, Accuracy and resolution of surface wave inversion: Recent Advances in Instrumentation, Data Acquisition and Testing in Dirt Dynamics, Geotechnical Special Publication No. 29, ASCE, 17-23.

Sanchez-Salinero, I., Roesset, J.M., Shao, KY., Stokoe II, K.H., and Rix, G.J., 1987, Analytical evaluation of variables affecting surface wave testing of pavements: Transportation research record No. 1136, 86-95.

Sheriff, R.E., 1991, Encyclopedic dictionary of exploration geophysics (third edition): Society of Exploration Geophysicists.

Sheriff, R.E., and Geldart, L.P., 1985, Exploration seismology (volume 1): History, theory, and data acquisition: Cambridge University Press, New York.

Sheu, J.C., Stokoe II, K.H., and Roesset, J.M., 1988, Effect of reflected waves in SASW testing of pavements: Transportation research record No. 1196, 51-61.

Song, Y.Y., Castagna, J.P., Black, R.A., and Knapp, R.W., 1989, Sensitivity of near-surface shear-wave velocity determination from Rayleigh and Love waves: Expanded Abstracts of the 59th Annual Meeting of the Society of Exploration Geophysicists, Dallas, Texas, 509-512.

Stokoe II, KH., and Nazarian, S., 1983, Effectiveness of ground improvement from Spectral Analysis of Surface Waves: Proceeding of the Eighth European Conference on Dirt Mechanics and Foundation Engineering, Helsinki, Finland.

Stokoe II, K.H., Rix, G J., and Nazarian, S., 1989, In situ seismic testing with surface wave: Processing, XII International Conference on Dirt Mechanics and Foundation Engineering, 331-334.

Stokoe II, K.H., Wright, G.W., Bay, J.A., and Roesset, J.M., 1994, Characterization of geotechnical sites by SASW method, in Geophysical characterization of sites, ISSMFE Technical Committee \#10, edited by R. D. Woods, Oxford Publishers, New Delhi.

Turner, M. A., 1990, Near-surface velocity reconstruction using surface wave inversion: M.S. thesis, Department of Geology and Geophysics, Univ. of Utah.

Xia, J., Miller, R. D., and Park, C. B., 1997, Estimation of shear wave velocity in a compressible Gibson half-space by inverting Rayleigh wave phase velocity: Technical Program with Biographies, SEG, 67th Annual Meeting, Dallas, TX, 1927-1920.

Xia, J., R.D. Miller, and C.B. Park, 1998, Construction of vertical seismic section of near-surface shearwave velocity from ground roll [Exp. Abs.]: Soc. Explor. Geophys./AEGE/CPS, Beijing, 29-33.

Xia, J., Miller, R.D., and Park, C.B., 1999, Estimation of near-surface shear-wave velocity by inversion of Rayleigh wave: Geophysics, 64, 691-700. 
Xia, J., Miller, R.D., and Park, C.B., 2000a, Advantage of calculating shear-wave velocity from surface waves with higher modes: Technical Program with Biographies, SEG, 70th Annual Meeting, Calgary, Canada, 1295-1298.

Xia, J., Miller, R.D., Park, C.B., Hunter, J.A., and Harris, J.B., 2000b, Comparing shear-wave velocity profiles from MASW technique with borehole measurements in unconsolidated sediments of the Fraser River Delta: Journal of Environmental and Engineering Geophysics, v. 5, no. 3, 1-13.

Xia, J., Miller, R.D., Park, C.B., and Ivanov, J., 2000c, Construction of 2-D vertical shear-wave velocity field by the multichannel analysis of surface wave technique: Proceedings of the Symposium on the Application of Geophysics to Engineering and Environmental Problems (SAGEEP 2000), Arlington, Va., February 20-24, 2000, 1197-1206. 